\title{
IGUALDADE E EDUCAÇÃO: INCLUSÃO DE PESSOAS COM DEFICIÊNCIA NA REDE REGULAR DE ENSINO E A RESPONSABILIDADE DAS INSTITUIÇÕES PRIVADAS
}

\author{
Stéphanie Nathanael Lemos ${ }^{1}$ \\ Thiago Penido Martins ${ }^{2}$
}

\section{Resumo}

O Estatuto da Pessoa com Deficiência foi instituído com o objetivo de promover a inclusão social de pessoas com deficiência, bem como garantir a elas o exercício dos direitos e das liberdades fundamentais. Como forma de garantia de acesso à educação, o art. $28, \S 1^{\circ}$, do Estatuto determinou aos estabelecimentos particulares a inclusão de alunos com deficiência na rede regular de ensino, ficando a cargo dos estabelecimentos as adaptações necessárias, sem repasse do ônus financeiro. Dessa obrigação, surgem questionamentos acerca da responsabilidade da educação "especial": é ela dever do Estado, ou deve ser compartilhada entre este e as instituições privadas?

Palavras-chave: Educação; Igualdade; Estatuto da Pessoa com Deficiência; Democracia; Inclusão.

\section{EQUALITY AND EDUCATION: INCLUSION OF PERSONS WITH DISABILITIES IN THE REGULAR EDUCATION SYSTEM AND RESPONSIBILITY OF PRIVATE INSTITUTIONS}

\begin{abstract}
The Statute of Persons with Disabilities was established with the objective of promoting the social inclusion of persons with disabilities, as well as guaranteeing them the exercise of fundamental rights and freedoms. As a form of guarantee of access to education, art. $28, \S 1^{\circ}$, of the Statute determined that private schools should include pupils with disabilities in the regular school system, with the necessary adjustments being made by the institutions, without any transfer of the financial burden. From this obligation, questions arise about the responsibility of "special" education: is it the duty of the State, or should it be shared between it and private institutions?
\end{abstract}

Keywords: Education; Equality; Statute of the Persons with Disabilities; Democracy; Inclusion.

\section{Introdução}

\footnotetext{
${ }^{1}$ Mestranda no Programa de pós-graduação Stricto Sensu da Universidade de Itaúna. Pós-graduada em Gestão Pública Municipal pela Universidade Federal de Uberlândia

${ }^{2}$ Doutor em Direito pela Pontifícia Universidade Católica de Minas Gerais. Mestre em Direito pela Faculdade de Direito Milton Campos. Especialista em Direito pela Faculdade de Direito Milton Campos
} 
Segundo dados da última pesquisa realizada pelo Instituto Brasileiro de Geografia e Estatística (IBGE), em 2010, há no Brasil mais de 45 milhões de pessoas que declararam ter pelo menos uma das formas de deficiência, seja visual, auditiva, motora ou intelectual. Assim, chega-se a conclusão que aproximadamente $23,9 \%$ da população brasileira possui algum tipo de deficiência. ${ }^{3}$

Nesse contexto, o Brasil ratificou a Convenção sobre os Direitos das Pessoas com Deficiência. Em razão da promulgação do Decreto Legislativo no $186 / 2008$, que conferiu às normas da Convenção sobre os Direitos das Pessoas com Deficiência natureza equivalente à de Emenda Constitucional, o ordenamento jurídico brasileiro tem se adaptado às exigências das novas normas. ${ }^{4}$

Com o propósito de assegurar e promover, em condições de igualdade, o exercício dos direitos e das liberdades fundamentais pelas pessoas com deficiência, foi promulgada a Lei Federal $n^{\circ}$ 13.146/2015, que entrou em vigor em janeiro de 2016, instituindo a Lei Brasileira de Inclusão da Pessoa com Deficiência, também conhecida como Estatuto da Pessoa com Deficiência (EPD).

Uma das principais características do Estatuto da Pessoa com Deficiência (EPD) é sua abrangência no tocante à proteção e à inclusão da pessoa com deficiência. Ao se ratificar a convenção mencionada, diversas obrigações foram assumidas pelo Estado, para garantir a equiparação de oportunidades entre pessoas com e sem deficiência em todo o território nacional.

Dentre estas, uma das mais relevantes é tornar a educação igualmente acessível a mais de 24 milhões de brasileiros com deficiência, algo que representa uma discussão extremamente relevante para a academia, haja vista que a implementação de medidas inclusivas ainda suscita questionamentos sobre possíveis abalos a garantias constitucionais de ordem individual. ${ }^{5}$

Nesse amplo cenário, interessa ao presente trabalho a discussão suscitada acerca dos preceitos contidos no artigo parágrafo primeiro, do artigo 28, do Estatuto da Pessoa com Deficiência, segundo o qual as instituições de ensino privada, de qualquer nível e modalidade, tem o dever de promover a inclusão de pessoas com deficiência no ensino regular, adotando,

\footnotetext{
${ }^{3}$ Convenção sobre os direitos das pessoas com deficiência.

${ }^{4}$ Nos termos do artigo $5^{\circ}$, $\S 3^{\circ}$, da Constituição da República: "Os tratados e convenções internacionais sobre direitos humanos que forem aprovados, em cada Casa do Congresso Nacional, em dois turnos, por três quintos dos votos dos respectivos membros, serão equivalentes às emendas constitucionais"

${ }^{5}$ Convenção sobre os direitos das pessoas com deficiência.
} 
para isso, as medidas de adaptação necessárias, sem que o ônus financeiro seja repassado às mensalidades, anuidades e matrículas.

Em decorrência os preceitos contidos no parágrafo primeiro, do artigo 28, da Lei Federal n. ${ }^{\circ}$ 13.146/2015, a Confederação Nacional dos Estabelecimentos de Ensino ajuizou, no Supremo Tribunal Federal, a Ação Direta de Inconstitucionalidade n. ${ }^{\circ}$ 5357. Fundamentou a Ação Direta de Constitucionalidade em diversos dispositivos da Constituição da República, argumentando, em síntese, que o referido dispositivo normativo viola diversos dispositivos constitucionais, dentre eles, o direito de propriedade, o princípio da livre iniciativa e aquele que prevê, como dever do Estado, o atendimento educacional aos deficientes.

Em junho de 2016, o Plenário do Supremo Tribunal Federal, julgou Ação Direta de Inconstitucionalidade . $^{\circ} 5357$ improcedente, declarando constitucional os preceitos contidos no parágrafo primeiro, do artigo 28, da Lei Federal n. ${ }^{\circ}$ 13.146/2015. Em que pese o posicionamento da Suprema Corte, os argumentos colecionados pela Confederação Nacional dos Estabelecimentos de Ensino não foram enfrentados a contento, de tal sorte que um número expressivo de questões semelhantes volta a ser levado à apreciação do Supremo Tribunal Federal.

Para se evitarem análises genéricas e superficiais da questão apresentada, optou-se, no presente trabalho, por delimitar a discussão à análise da responsabilidade pela educação de pessoas com deficiência. Mas será que a responsabilidade pela educação de pessoas com deficiência é dever do Estado, ou esse dever é compartilhado com particulares? A resposta a esse questionamento exige, além da compreensão do texto constitucional, respostas a outras perguntas, tais como: Qual a importância histórica do direito à educação? Qual a relevância do direito à educação para o desenvolvimento da democracia no ordenamento jurídico brasileiro? Quais outros direitos influenciam ou são influenciados pelo direito à educação?

Para que os objetivos do presente trabalho fossem alcançados à contento, dividiu-se o testudo em 4 tópicos, incluindo a presente introdução. No segundo tópico, procedeu-se à análise da Lei Federal $n^{\circ}$ 13.146/2015 (EPD), destacando-se os compromissos internacionais assumidos pelo Estado brasileiro e os objetivos pretendidos com a sua promulgação, com especial destaque para os preceitos legais contidos no parágrafo primeiro, do artigo 28 , bem como as subsequentes alterações introduzidas no ordenamento jurídico pátrio, relacionadas e necessárias à compreensão do tema.

No terceiro tópico, de forma abrangente, realizou-se breve histórico da evolução dos direitos fundamentais, analisando o direito à educação como uma conquista histórica mundial, 
classificando-o quanto à sua natureza e características, bem assim destacando sua essencial importância à estrutura do Estado, mecanismo para o desenvolvimento da sociedade e da democracia. São também analisados o direito fundamental à igualdade e o princípio dignidade da pessoa humana, como princípios constitucionais justificadores da inclusão social.

No quarto tópico, em que pese o reconhecimento da importância e necessidade da criação das políticas inclusivas em matéria de acesso da pessoa com deficiência ao sistema de ensino regular, procedeu-se a breves considerações e análises criticas acerca de aspectos que não foram objetos de debate quando do julgamento da Ação Direta de Inconstitucionalidade n. ${ }^{\circ}$ 5357, especificamente, a discussão sobre a extensão e limites da responsabilidade das instituições privadas de ensino em promover a inclusão das pessoas com deficiência, face à ausência de mecanismos de contrapartida estatal, de modo a evitar a mera transferência de obrigações estatais aos particulares, em detrimento da natureza colaborativa de sua atuação.

No presente artigo, utilizou-se da pesquisa teórico-bibliográfica, tendo em vista que a construção do debate teórico se embasa, em grande parte, em doutrinadores que discutiram o tema ora posto. No que tange ao procedimento metodológico, optou-se pelo método indutivo, haja vista partir-se de uma concepção micro para uma concepção macro analítica, permitindose, portanto, a delimitação do problema teórico. Finalmente, no procedimento técnico, foram adotadas as análises interpretativas, comparativas, históricas e temáticas, possibilitando uma discussão pautada sob o ponto de vista da crítica científica.

\section{Estatuto da Pessoa com Deficiência - Lei Federal n. ${ }^{\circ}$ 13.146/2015}

Por intermédio do Decreto Legislativo $n^{\circ} 186 / 2008$, foi incorporada à legislação brasileira a Convenção sobre os Direitos das Pessoas com Deficiência, assinada na Cidade de Nova Iorque, em 2007. Os preceitos contidos na referida convenção se deu com natureza equivalente à de emenda constitucional, na forma do parágrafo terceiro, do artigo $5^{\circ}$, da Constituição da República, conferindo ao conteúdo da convenção aplicação imediata, revogando-se automaticamente todas as normas por ventura contrárias, e impondo-se interpretação de forma a fazer valer o documento internacional (ONU, 2006). Em agosto de 2009, por meio do Decreto $\mathrm{n}^{\circ}$ 6.949, a Convenção sobre os Direitos das Pessoas com Deficiência foi promulgada.

O legislador ordinário, em decorrência da convenção promulgada, acrescentou ao ordenamento jurídico brasileiro às disposições nela contidas, editando a Lei Federal $n^{\circ}$ 
13.146/2015, que entrou em vigor em janeiro de 2016, instituindo, assim, a Lei Brasileira de Inclusão da Pessoa com Deficiência, também conhecido como Estatuto da Pessoa com Deficiência (EPD). De acordo com seu artigo $1^{\circ}$, a legislação se destina a assegurar e a promover, em condições de igualdade, o exercício dos direitos e das liberdades fundamentais por pessoa com deficiência, visando à sua inclusão social e cidadania.

Em seu artigo $2^{\circ}$, o Estatuto da Pessoa com Deficiência (EPD) conceitua a pessoa com deficiência como aquela que tem impedimento de longo prazo de natureza física, mental, intelectual ou sensorial, o qual, em interação com uma ou mais barreiras, pode obstruir sua participação plena e efetiva na sociedade em igualdade de condições com as demais pessoas. Como se observa, o Estatuto é abrangente no tocante à proteção e à inclusão da pessoa com deficiência, inclusive contendo regras e orientações que visam garantir, dentre outros direitos, o acesso à educação.

No que tange ao direito à educação, o Estatuto da Pessoa com Deficiência (EPD) dedicou-lhe um Capítulo IV (arts. 27 à 30), estabelecendo no artigo 27, ser a educação direito da pessoa com deficiência, assegurados sistema educacional inclusivo em todos os níveis e aprendizado ao longo de toda a vida, de forma a alcançar o máximo desenvolvimento possível de seus talentos e habilidades físicas, sensoriais, intelectuais e sociais, segundo suas características, interesses e necessidades de aprendizagem.

A principal e mais polêmica norma contida no Estatuto da Pessoa com Deficiência (EPD) é a que estabelece às escolas privadas a obrigatoriedade de atender alunos com deficiência, sem que haja qualquer transferência de ônus financeiros aos familiares, devendo a instituição de ensino suportar e absorver os custos com a inclusão e adaptação da pessoa com deficiência.

Consoante preceitos legais contidos no parágrafo primeiro, do artigo 28, do Estatuto da Pessoa com Deficiência (EPD), devem as instituições privadas de ensino, de qualquer nível e modalidade, promover a inserção de pessoas com deficiência no ensino regular, promovendo para tanto, as medidas de adaptação necessárias, sem que o ônus financeiro seja repassado às mensalidades, anuidades e matrículas.

Art. 28. Incumbe ao poder público assegurar, criar, desenvolver, implementar, incentivar, acompanhar e avaliar:

(...) 
$\S 1^{\mathrm{o}}$ Às instituições privadas, de qualquer nível e modalidade de ensino, aplica-se obrigatoriamente o disposto nos incisos I, II, III, V, VII, VIII, IX, X, XI, XII, XIII, XIV, XV, XVI, XVII e XVIII do caput deste artigo, sendo vedada a cobrança de valores adicionais de qualquer natureza em suas mensalidades, anuidades e matrículas no cumprimento dessas determinações.

No termos do preceito legal colacionado, as instituições privadas de ensino deverão, similarmente ao poder público, adotar as seguintes medidas:

a) criar sistema educacional inclusivo em todos os níveis e modalidades, bem como o aprendizado ao longo de toda a vida;

b) propiciar o aprimoramento dos sistemas educacionais, visando a garantir condições de acesso, permanência, participação e aprendizagem, por meio da oferta de serviços e de recursos de acessibilidade que eliminem as barreiras e promovam a inclusão plena; elaborar projeto pedagógico que institucionalize o atendimento educacional especializado, assim como os demais serviços e adaptações razoáveis, para atender às características dos estudantes com deficiência e garantir o seu pleno acesso ao currículo em condições de igualdade, promovendo a conquista e o exercício de sua autonomia;

c) adotar medidas individualizadas e coletivas em ambientes que maximizem o desenvolvimento acadêmico e social dos estudantes com deficiência, favorecendo o acesso, a permanência, a participação e a aprendizagem em instituições de ensino;

d) realizar o planejamento de estudo de caso, de elaboração de plano de atendimento educacional especializado, de organização de recursos e serviços de acessibilidade e de disponibilização e usabilidade pedagógica de recursos de tecnologia assistiva;

e) participação dos estudantes com deficiência e de suas famílias nas diversas instâncias de atuação da comunidade escolar;

f) adoção de medidas de apoio que favoreçam o desenvolvimento dos aspectos linguísticos, culturais, vocacionais e profissionais, levando-se em conta o talento, a criatividade, as habilidades e os interesses do estudante com deficiência;

g) adoção de práticas pedagógicas inclusivas pelos programas de formação inicial e continuada de professores e oferta de formação continuada para o atendimento educacional especializado;

h) formação e disponibilização de professores para o atendimento educacional especializado, de tradutores e intérpretes da Libras, de guias intérpretes e de profissionais de apoio;

i) oferta de ensino da Libras, do Sistema Braille e de uso de recursos de tecnologia assistiva, de forma a ampliar habilidades funcionais dos estudantes, promovendo sua autonomia e participação;

j) acesso à educação superior e à educação profissional e tecnológica em igualdade de oportunidades e condições com as demais pessoas;

1) inclusão em conteúdos curriculares, em cursos de nível superior e de educação profissional técnica e tecnológica, de temas relacionados à pessoa com deficiência nos respectivos campos de conhecimento;

m) acesso da pessoa com deficiência, em igualdade de condições, a jogos e a atividades recreativas, esportivas e de lazer, no sistema escolar;

n) acessibilidade para todos os estudantes, trabalhadores da educação e demais integrantes da comunidade escolar às edificações, aos ambientes e às atividades concernentes a todas as modalidades, etapas e níveis de ensino; 
o) oferta de profissionais de apoio escolar;

p) articulação intersetorial na implementação de políticas públicas.

Em que pese a polêmica apresentada, em especial, quanto a constitucionalidade da transferência de obrigações do poder público às instituições privadas de ensino sem a previsão de qualquer contrapartida, é inegável que o Estatuto da Pessoa com Deficiência (EPD) representou um grande avanço no que diz respeito a inclusão social da pessoa com deficiência. Em consequência, inúmeros segmentos da sociedade deverão se adaptar à nova realidade, bem como deverão ser adaptados os serviços, públicos e privados, para garantirem de forma plena e efetiva participação de pessoa com deficiência com igualdade de oportunidades.

\section{Evolução dos Direito Fundamentais}

A edificação de uma doutrina dos direitos e garantias fundamentais, bem como a estrutura tridimensional classificatória das dimensões dos direitos fundamentais, coincide com o final do século XVIII sendo influenciada pela Revolução Francesa e pelos pensadores iluministas, que fizeram do lema Liberté, Igualité, Fraternité, ideais que ecoaram pelo mundo na luta contra a exploração das classes menos favorecidas, influenciando a Declaração dos Direitos do Homem e do Cidadão de 1948 (BERGARA e GONÇALVES, 2008).

Os direitos fundamentais compreendem a base de qualquer sociedade que tenha como princípios norteadores a justiça e a igualdade. São direitos inerentes a toda pessoa. Consoante a clássica classificação em dimensões, esses direitos se dividem em: a) direitos de primeira dimensão (liberdade); b) direitos de segunda dimensão (igualdade) e c) direitos de terceira dimensão (fraternidade) (BONAVIDES, 2004, p. 560-578). ${ }^{6}$ Há doutrinadores que defendem a classificação dos direitos fundamentais também em sua quarta e quinta gerações. ${ }^{7}$

\footnotetext{
${ }^{6}$ Estudiosos dos direitos fundamentais costumam fazer referência à existência de gerações ou dimensões de direitos para tentar explicar o processo de evolução dos direitos fundamentais no Estado Moderno. Se o modelo geracional ou dimensional de classificação dos direitos fundamentais traz consigo a vantagem de ser didático, ao facilitar a compreensão do fenômeno da evolução dos direitos fundamentais, salienta-se não sê-lo um modelo uniforme nem preciso, que nem sempre consegue explicar adequadamente a evolução dos direitos fundamentais em todos os Estados de Direito. Salienta MELLO que: "Com efeito, as classificações históricas valeram-se da categoria de gerações de direitos para explicar a evolução dos direitos fundamentais, concepção que poderá ser útil à historiografia do constitucionalismo, mas que passa a errada impressão de que uma geração de direitos substitui ou sucede a anterior, quando todo o fenômeno dos direitos fundamentais na história consiste num permanente acrescentar novas espécies jusfundamentais às já reconhecidas. A história dos direitos fundamentais é uma história de densificação e ampliação, não de sucessão.” (2001, p. 239) No mesmo sentido
} 
Os direitos compreendidos na primeira geração são os direitos individuais, também conhecidos como direitos de liberdade, de natureza civil e política. Segundo Bobbio (1992, p. 32-33), a primeira geração contempla direitos de liberdade, pois tinham como fundamento a limitação do poder Estatal e a reserva para o particular de garantias mínimas para uma vida livre, originando para o Estado uma obrigação negativa, de não fazer. Os direitos de primeira geração surgiram com a ideia de Estado de Direito. ${ }^{8}$

Após a Primeira Guerra Mundial, com o avanço do liberalismo político e econômico no início do século XX, o mundo assistiu à deterioração do quadro social, com agravamento das desigualdades sociais. Ante a degradação do próprio homem, há o advento de um novo modelo de Estado, o Estado Social de Direito. Os direitos de segunda geração, associados a esse cenário, estão diretamente ligados aos direitos sociais, por objetivarem a melhoria das condições de vida e de trabalho da população, promovendo uma vida digna, eliminando o cenário de extrema exploração do homem pelo homem.

Essa nova geração reclama do Estado ações positivas, que possam proporcionar condições mínimas de vida digna. Trata-se dos direitos sociais, econômicos e culturais, que sempre buscam diminuir as desigualdades sociais, notadamente proporcionando proteção aos mais fracos, como preceitua o princípio da igualdade. De nada adiantaria garantir formalmente direitos individuais, se a maior parte dos indivíduos não possuía meios para exercê-los, ou seja, se não lhe eram garantidos os direitos trabalhistas, previdenciários, o acesso à educação, à saúde.

Os direitos de terceira geração correspondem à fraternidade ou à solidariedade, integrando a titularidade de grupos humanos como a família, a sociedade e a coletividade. A nova sociedade de massas passa a exigir a proteção e tutela dos interesses da coletividade,

GOMES: "Denota-se dessa interação expansionista dos direitos fundamentais a necessidade de uma abordagem holística, de modo que as distinções entre os mesmos baseadas nas gerações e nas dimensões individuais e coletivas figuram como partimentalizações inadequadas. Assim, além da reafirmação de que todos os direitos humanos são interdependentes e inter-relacionados, a abordagem holística reconhece que todos eles são essenciais, estão sujeitos a violações, e à realização de cada um deles possui caráter instrumental na realização dos demais." (2003, p. 128).

${ }^{7}$ Nesse sentido é a obra de BONAVIDES (2008). Outros autores também sustentam a existência de uma quarta geração de direitos fundamentais, tais como COMPARATO (2001); LAFER (2010) PIOVESAN (2012).

${ }^{8}$ GALDINO, com base nas obras de HOLMES e CARL SUNSTEIN, faz a ressalva de que todos os direitos fundamentais demandam prestações estatais, razão pela qual seria incorreta a pressuposição de que os direitos individuais, também denominados liberdades negativas, seriam garantidos a partir da mera abstenção estatal. Conforme preleciona o autor; "E o que se põe diante dos olhos com clareza capaz de ofuscar é a certeza de que todos os direitos subjetivos públicos são positivos. As prestações necessárias à efetivação de tais direitos têm custos e, como tal, são sempre positivas. Não há falar, portanto, em direitos fundamentais negativos ou, o que é ainda pior, em direitos fundamentais gratuitos." (2005, p. 346). 
integrada nacional e internacionalmente. São incorporados aos textos constitucionais direitos de solidariedade ${ }^{9}$ ou fraternidade, caracterizados pela sua natureza eminentemente coletiva e difusa, como o direito ao meio ambiente, o direito do consumidor, o direito à proteção do patrimônio histórico e cultural. Leciona BONAVIDES:

\begin{abstract}
Dotados de altíssimo teor de humanismo e universalidade, os direitos da terceira geração tendem a cristalizar-se neste fim de século enquanto direitos que não se destinam especificamente à proteção dos interesses de um indivíduo, de um grupo, ou de um determinado Estado. Têm primeiro por destinatário o gênero humano mesmo, num momento expressivo de sua afirmação como valor supremo em termos de existencialidade concreta. Os publicistas e juristas já o enumeram com familiaridade, assinalando-lhe o caráter fascinante de coroamento de uma evolução de trezentos anos na esteira da concretização dos direitos fundamentais. Emergiram eles da reflexão sobre temas referentes ao desenvolvimento, à paz, ao meio ambiente, à comunicação e ao patrimônio comum da humanidade. (2004, p. 569570).
\end{abstract}

O direito à educação é classificado como de segunda dimensão, dada sua natureza social e prestacional, exigindo que o poder público implemente ações positivas que garantam, frente à sociedade, o acesso igualitário. Pertencem também a essa dimensão de direitos, os direitos sociais, econômicos e culturais, voltados para a diminuição das desigualdades sociais, notadamente ao proporcionar proteção aos mais fracos, como expressão maior do princípio constitucional da igualdade.

\title{
3.1 Direito Fundamental à Educação
}

A educação, ao ser prevista no artigo XXVI da Declaração dos Direitos do Homem e do Cidadão de 1948, assume a qualidade de direito humano universal e, portanto, fundamental no plano normativo nacional. A Constituição da República, ao incorporar tal declaração e inserir o direito à educação no capítulo II de seu texto, referente aos direitos sociais, confirma a educação como um direito fundamental social, destinado a proporcionar condições mínimas de dignidade e minimizar as desigualdades sociais, por meio de ações positivas, concretizando o princípio da igualdade.

\footnotetext{
9 A expressão direitos de solidariedade é atribuída a Karel Vasak, durante a abertura dos cursos do Instituto Internacional dos Direitos do Homem em 1979. De acordo com GUERRA FILHO, os direitos de solidariedade são aqueles "que impõe ao Estado, e também a outras entidades coletivas da sociedade, o respeito a interesses individuais, bem como coletivos e difusos, à fruição de bens insusceptíveis de apropriação individual, quando integrarem, por exemplo, o patrimônio histórico, cultural e natural comum." (2001, p. 112)
} 
Os valores e as ideologias que embalam e norteiam a Constituição da República repercutem, por óbvio, no direito fundamental à educação. De modo especial e diferentemente dos demais direitos fundamentais sociais positivados, a educação, na Constituição da República, corretamente intitulada de Constituição Cidadã, foi objeto de regulamentação detalhada, o que representou grande avanço frente às Cartas anteriores, dando maior destaque e proteção ao seu conteúdo, inclusive com a distribuição pormenorizada de competências entre os entes federativos.

A Constituição da República, no seu artigo $6^{\circ}$, consagra a educação como um direito social. Destaca Pessoa (2011) a relevância dada ao direito à educação, "como sendo um dos mais importantes, por ter objetivos de criar para a nossa sociedade indivíduos capazes de desenvolver, pessoas que adquiram o mínimo necessário para a sua sobrevivência em sociedade". Foi a primeira vez que uma constituição brasileira explicitou de modo detalhado uma declaração de Direitos Sociais, destacando-se, com primazia, direito fundamental à educação.

Destacado o reconhecimento jurídico conferido ao direito à educação, imperioso analisar detidamente o texto constitucional, com o objetivo de identificar a quem e em que medida foi atribuído o dever constitucional de promover e garantir a educação especial às pessoas com deficiência, em especial mediante a análise e estudo dos preceitos constitucionais contidos nos artigos 205 à 214, da Constituição da República, dentre outros esparsos no seu texto.

A Constituição da República, em seu artigo 205, preceitua ser a educação um direito de todos e dever do Estado e da família, que será promovida e incentivada com a colaboração da sociedade. ${ }^{10}$ Em seu capítulo IV, a Constituição da República, ao tratar dos direitos da criança, do adolescente e do jovem (artigo 227), afirma mais uma vez ser dever da família, da sociedade e do Estado assegurar àqueles o direito à educação. ${ }^{11}$ No parágrafo primeiro, inciso II, do mesmo artigo, atribui expressamente ao Estado a incumbência de promover a criação de

\footnotetext{
${ }^{10}$ Art. 205. A educação, direito de todos e dever do Estado e da família, será promovida e incentivada com a colaboração da sociedade, visando ao pleno desenvolvimento da pessoa, seu preparo para o exercício da cidadania e sua qualificação para o trabalho.

${ }^{11}$ Art. 227. É dever da família, da sociedade e do Estado assegurar à criança, ao adolescente e ao jovem, com absoluta prioridade, o direito à vida, à saúde, à alimentação, à educação, ao lazer, à profissionalização, à cultura, à dignidade, ao respeito, à liberdade e à convivência familiar e comunitária, além de colocá-los a salvo de toda forma de negligência, discriminação, exploração, violência, crueldade e opressão.
} 
programas de prevenção e atendimento especializado para as pessoas portadoras de deficiência física. ${ }^{12}$

O artigo 208, inciso III, da Constituição da República, preceitua que o dever do Estado para com a educação será efetivado mediante a garantia de atendimento educacional especializado aos portadores de deficiência, preferencialmente na rede regular de ensino, nela compreendido o ensino ministrado tanto em estabelecimentos públicos, como em particulares. Há que se destacar, ainda, os preceitos contidos no artigo 58 da Lei ${ }^{\circ}$ 9.394/96, Lei de Diretrizes e Bases da Educação Nacional (LDB), também aplicável às instituições privadas de ensino, por força do inciso I, do artigo 209, da Constituição da República, os quais afirmam ser livre o ensino à iniciativa privada, cumpridas as normas gerais da educação nacional.

Os preceitos constitucionais supramencionados foram apontados pelos autores da Ação Direta de Inconstitucionalidade n. ${ }^{\circ}$ 5357, como justificadores do dever estatal de prestar a educação especializada e, consequentemente, da arguição de inconstitucionalidade do parágrafo primeiro, do artigo 28, da Lei Federal n ${ }^{\circ}$ 13.146/2015, denominada de Estatuto da Pessoa com Deficiência (EPD). Em junho de 2016, o Plenário do Supremo Tribunal Federal, julgou Ação Direta de Inconstitucionalidade n. ${ }^{\circ} 5357$ improcedente, declarando constitucional os preceitos contidos no parágrafo primeiro, do artigo 28, da Lei Federal n. ${ }^{\circ}$ 13.146/2015.

\subsection{A igualdade e a dignidade da pessoa humana como fundamentos da inclusão social}

Ao se tratar do direito fundamental à educação, a igualdade que se busca é a material, aquela que corresponde ao ideal de justiça preconizado no preâmbulo constitucional. Para Rocha (2016), a igualdade material na educação inclusiva é vista quando se propõe garantir o atendimento educacional especializado aos portadores de deficiência, preferencialmente na rede regular de ensino (art. 208, III). O autor destaca a importância de se observar a expressão "preferencialmente" constante da norma constitucional. Para ele, a expressão não deve ser entendida como uma escolha das escolas em aceitar ou não educandos com deficiência, faculdade que resultaria em segregação, que não é o objetivo do Estado.

\footnotetext{
$12 \S 1^{\circ} \mathrm{O}$ Estado promoverá programas de assistência integral à saúde da criança, do adolescente e do jovem, admitida a participação de entidades não governamentais, mediante políticas específicas e obedecendo aos seguintes preceitos: (...) II - criação de programas de prevenção e atendimento especializado para as pessoas portadoras de deficiência física, sensorial ou mental, bem como de integração social do adolescente e do jovem portador de deficiência, mediante o treinamento para o trabalho e a convivência, e a facilitação do acesso aos bens e serviços coletivos, com a eliminação de obstáculos arquitetônicos e de todas as formas de discriminação.
} 
No mesmo sentindo, Santos (2012) relata que, "inicialmente, pregava-se que o ensino deveria ser ministrado às pessoas com deficiência em estabelecimentos ou salas diferenciadas, excluindo-as do convívio regular com os outros alunos”. Todavia, em virtude da necessidade de integrar a pessoa com deficiência ao convívio normal, não mais se admite tal discriminação. Assim, no que tange ao direito fundamental à educação inclusiva, quando o constituinte propõe atendimento especial na perspectiva de acesso à rede regular de ensino, busca alcançar condições de igualdade entre os alunos numa mesma sala de aula, coibindo qualquer forma de discriminação. (ROCHA 2016).

Atique e Veltroni (2011), ao comentarem sobre a preferência determinada na Constituição, pelo atendimento especializado para as pessoas portadoras de deficiência física, na rede regular de ensino, destacam a caracterização da intenção do legislador constituinte de incluir a pessoa deficiente no cerne da sociedade, apoiando a convivência e o respeito a eles. Destacam ainda que, por ser a educação um direito social fundamental, garante à pessoa deficiente os direitos constitucionalmente garantidos, em virtude do princípio da isonomia, consubstanciado no direito à igualdade, princípio basilar da dignidade da pessoa humana e fundamento máximo do ordenamento jurídico.

\subsection{Educação inclusiva como elemento essencial para o desenvolvimento da democracia}

Nesse ínterim, a educação deve ser voltada para o convívio plural e na aceitação da diversidade, no respeito à dignidade da pessoa humana e na preocupação com a justiça social. Para Gomes (2011), a educação "é capaz de libertar o indivíduo e os povos das amarras da ignorância a respeito de seus próprios direitos, valores e dignidade, bem como sobre os direitos, valores e a dignidade do outro, de modo a ver neste um semelhante e não um inimigo". A Constituição da República, ao proclamar a educação como um direito fundamental de natureza social, faz com que a sua abrangência ultrapasse a esfera do interesse individual, deixando de priorizar o indivíduo, para buscar proteger o bem comum, ou seja, o interesse coletivo, acarretando ao Estado o dever objetivo de torná-los realidade.

Ao se considerar o acesso à educação uma expressão do direito de igualdade, lema vinculado aos direitos sociais, compartilha também a educação dos mesmos fundamentos históricos dos demais direitos assim classificados. Direitos ora classificados como sociais surgiram em contraponto ao avanço do liberalismo político e econômico consagrado pelo Estado de Direito, em que a classe dominante burguesa, buscando a limitação do poder 
Estatal, reivindicava direitos de liberdade (direitos de primeira geração). Surge então o Estado Social de Direito, diretamente ligado aos direitos sociais, que tinha por objetivo proporcionar a melhoria das condições de vida e de trabalho da população do Estado. Nesse cenário, buscase diminuir as desigualdades sociais, exigindo do Estado ações positivas de proteção aos mais fracos e às minorias, garantido a esses maior igualdade de participação na construção das políticas públicas e efetivação do princípio de igualdade.

De forma muito clara, SILVA sintetiza a razão pela qual os direitos de igualdade não constituíram reivindicações expressivas no regime liberal:

É que a igualdade constitui o signo fundamental da democracia. Não admite os privilégios e distinções que um regime simplesmente liberal consagra. Por isso é que a burguesia, cônscia de seu privilégio de classe, jamais postulou um regime de igualdade tanto quanto reivindicara o de liberdade. É que em regime de igualdade contraria seus interesses e dá à liberdade sentido material que não se harmoniza com o domínio de classe em que assenta a democracia liberal burguesa. (2005, p. 211)

Reflexo da democracia liberal burguesa, os textos constitucionais, até então, só consagravam a igualdade jurídico-formal, ou seja, a igualdade perante a lei. Na tentativa de promover uma igualdade material, a Constituição da República dedica um capítulo aos direitos individuais (art. $5^{\circ}$ ), afirmando serem todos iguais perante a lei, sem distinção de qualquer natureza. Reforça o princípio da igualdade material e demostra preocupação com a justiça social ao trazer, como objetivo fundamental do Estado brasileiro, a redução das desigualdades sociais e regionais, ainda que programaticamente, repulsando veementemente qualquer forma de discriminação (art. 3º III e IV) (SILVA, 2005, p. 211 e 212).

De forma indubitável, o preâmbulo constitucional, destaca a finalidade do Estado Democrático brasileiro de assegurar a igualdade e a justiça como valores supremos da sociedade. Por essas razões, já se pode concluir ser objetivo do estado democrático, dever estatal, perquirir a justiça social, a qual compreende promover a igualdade material em suas diversas facetas, por constituírem valores supremos do Estado brasileiro. Nesse propósito, é objetivo fundamental da República construir uma sociedade livre, justa e solidária, bem como reduzir as desigualdades sociais e regionais, promovendo o bem de todos quaisquer formas de preconceito e discriminação (art. $3^{\circ}$, I, II e IV da CF/88). Tais objetivos não podem ser alcançados apenas por meio da igualdade formal. Promover a igualdade material demanda atuação positiva do Estado, pressupõem a realização de ações afirmativas, que garantam concretude e efetividade das condições. 
Nesse sentido, MELO (2011) afirma que:

(...) a igualdade tem que ser compreendida a partir da somatória da igualdade formal e material. Ou seja, não basta a não-discriminação. Para que possamos atingir uma situação de igualdade, é preciso que invistamos em mecanismos de garantia de igualdade de fato, instrumentos conhecidos por ações afirmativas e discriminação positiva (...). Neste sentido de igualdade, o Estado assume uma postura ativa, de quem está obrigado a implementar prestações positivas para a satisfação da igualdade e não apenas limitado a se abster e não intervir, nos moldes do Estado Liberal Clássico.

É nesse viés que Silva (2005, p. 214) justifica o legislador progressivamente publicar leis setoriais para poder levar em conta diferenças nas formações e nos grupos sociais, pois lei geral, abstrata e impessoal incide em todos igualmente, levando em conta apenas a igualdade dos indivíduos e não a igualdade dos grupos, o que acaba por gerar mais desigualdades e propiciar injustiça. Desse modo, o legislador, ao editar o Estatuto da Pessoa com Deficiência (EPD), considera a desigualdade desse grupo de pessoas para a promoção de ações afirmativas no que tange ao processo de inclusão social da pessoa deficiente na rede regular de ensino. Sob a perspectiva da justiça social, o Estado cumpre seu papel democrático ao garantir a igualdade material.

\section{Análise critica da Ação Direta de Inconstitucionalidade n..$^{0}$ 5357: transferência de obrigações ou atuação colaborativa?}

A breve análise dos votos proferidos na Ação Direta de Inconstitucionalidade n. ${ }^{\circ} 5357$ permite inferir que, em momento algum, foi realizada uma profunda discussão acerca da extensão da responsabilidade das instituições privadas de ensino na consecução das ações descritas nos incisos I, II, III, V, VII, VIII, IX, X, XI, XII, XIII, XIV, XV, XVI, XVII e XVIII, do caput, do artigo 28, do Estatuto da Pessoa com Deficiência (EPD), o que seria imprescindível, uma vez que os referidos incisos materializam diversas ações e condutas, cuja natureza e características são completamente distintas.

A leitura dos incisos, do caput, do artigo 28, do Estatuto da Pessoa com Deficiência (EPD), permite inferir que o cumprimento de algumas das obrigações ali previstas dependem de condutas negativas, abstenções, obras de infraestrutura, ou ações de planejamento e gestão educacional e institucional, que não exigirão da instituição privada de ensino consideráveis investimentos econômicos e o aporte de recursos. Outras obrigações, todavia, dependerão, para sua satisfação, do aporte de recursos pela instituição privada de ensino, tal como quando 
se exige a oferta de ensino de Libras, do Sistema Braille e de uso de recursos de tecnologia assistiva e a oferta de profissionais de apoio escolar.

Assim, o que se apresenta como ponto controvertido, a ser discutido com mais profundidade, é o fato de que os preceitos contidos no parágrafo único, do artigo 28 , do Estatuto da Pessoa com Deficiência (EPD), simplesmente transferem à iniciativa privada deveres que são próprios e inerentes ao poder público ${ }^{13}$, sem criar mecanismos de compensação, contrapartida ou subsídio, com o desiderato de assegurar o equilíbrio econômico-financeiros dos contratos de prestação de serviços educacionais celebrados com as instituições privadas de ensino, em especial, considerando a vedação de repasse dos ônus aos pais ou familiares.

Note-se, que o que se está a questionar a necessidade e relevância de mecanismos de inclusão social, especialmente em matéria de acesso à educação, um dos direitos sociais mais elementares para a formação humana, mas apenas analisar a adequação da forma escolhida pelo legislador, bem como apontar a necessidade de se criar políticas de incentivo à implementação das obrigações estabelecidas. Primeiro, porque é difícil ou quase impossível controlar e identificar a transferência dos custos com a inclusão do aluno com deficiência, embutindo-o nas matrículas e mensalidades dos demais alunos, pelo mecanismo do preço, tornando ineficaz a vedação de repasse do ônus aos pais ou familiares.

Segundo, pelo fato de que, ao não se estabelecer nenhum mecanismo de compensação, contrapartida ou subsídio, destinados à estimular e incentivar a prática voluntária das condutas desejadas pelos particulares, acaba-se por transferir compulsoriamente obrigações do poder público às instituições privadas de ensino, desvirtuando a natureza colaborativa da atuação da sociedade (iniciativa privada) na promoção da educação, tal como preceituado pelo artigo 205, da Constituição da República.

Conforme destaca Stern, mesmo nas relações entre particulares em que há uma desigualdade fática entre os sujeitos de direito envolvidos, não há como igualá-la a uma relação entre indivíduo e o poder estatal, já que não resta afastado do caráter jurídico-privado

\footnotetext{
${ }^{13}$ Note-se que o artigo 205, da Constituição da República, preceitua ser a educação direito de todos e dever do Estado e da família, devendo ser promovida e incentiva com a colaboração da sociedade. Por sua vez, no inciso III, do artigo 208, da Constituição da República estabelece ser dever do Estado o atendimento educacional especializado aos portadores de deficiência, preferencialmente na rede regular de ensino. Já no parágrafo primeiro, inciso II, de seu artigo 227, a Constituição da República preceitua que o Estado criará de programas de prevenção e atendimento especializado para as pessoas portadoras de deficiência física, sensorial ou mental, bem como de integração social do adolescente e do jovem portador de deficiência, mediante o treinamento para o trabalho e a convivência
} 
da relação, bem como a nota de subordinação, peculiar as relações jurídicas que envolvem o poder público (STERN, 1987). ${ }^{14}$ Desse modo, a extensão ou transferência aos particulares de obrigações inerentes ao poder público deve ocorrer de forma equilibrada.

Nesse sentido, importante destacar excerto do voto preferido pelo Ministro Marco Aurélio na ADI 1.950, cujo objeto era a análise da constitucionalidade de lei estadual que previa a obrigação de particulares de garantirem a estudantes o direito ao pagamento de meiaentrada em espetáculos esportivos, culturais e de lazer. Segundo destacou o Ministro:

\begin{abstract}
(...) essa forma de dispor, entretanto, com interferência de fundo na livre iniciativa, sem uma contrapartida, cumprimentando o Estado - e a premissa é esta - com chapéu alheio, é consentânea com a Constituição Federal? (...) Não vejo como se fixar esse ônus, que acaba sendo suportado, ante a transferência, pela sociedade, tendo em conta a majoração da entrada para aqueles que não gozam do benefício, mediante uma norma, repito, não razoável, porque nela não se contém a contrapartida, ou seja, uma compensação - havendo uma desvantagem significativa - da perda por aqueles que se lançam ao mercado, na vida comercial, e precisam fugir à morte civil nesta mesma vida comercial, que é a falência."(BRASIL, STF, ADI 1.590/SP, Rel. Eros Grau, Pleno, Dj 03/11/2005)
\end{abstract}

Nesse diapasão, para que não haja o desvirtuamento da participação colaborativa da sociedade na promoção do direito à educação, decorrente da transferência direta de obrigações do poder público aos particulares, indispensável que o Estado crie mecanismos e instrumentos de compensação, contrapartida ou subsídio destinados a assegurar o equilíbrio econômicofinanceiro dos contratos de prestação de serviços educacionais, estimulando as condutas sociais que reputa desejáveis, de modo à assegurar a efetividade das políticas de inclusão das pessoas com deficiência, da promoção da educação e da garantia da livre iniciativa.

\title{
5 Considerações Finais
}

A Educação, consagrada como direito universal do homem na Declaração dos Direitos do Homem e do Cidadão de 1948 e incorporada na Carta de 1988 aos direitos sociais fundamentais, foi especialmente regulamentada em seção especial. Todavia, o detalhamento não exaure o conteúdo normativo. Dentre outras normas, complementam a regulamentação de tal direito a Lei n ${ }^{\circ}$ 9.394/96, Lei de Diretrizes e Bases da Educação Nacional (LDB), e outras

\footnotetext{
${ }^{14}$ Segundo SAMENTO: "Em principio, a harmonização entre os deveres de solidariedade e o espaço de liberdade dos particulares é tarefa para o legislador, como instância democraticamente legitimada para proceder a complexas ponderações de interesse, envolvendo valore tão abstratos e incorpóreos. O legislador não só pode, como em alguns casos, está constitucionalmente obrigado a editar normas que imponham aos agentes privados certos deveres sociais." (SARMENTO, 2008, p. 297).
} 
mais, como é o caso do Estatuto da Pessoa com Deficiência, que tem o condão de modificar toda a legislação que lhe for contrária materialmente.

Com a entrada em vigor do Estatuto da Pessoa com Deficiência (Lei $\mathrm{n}^{\circ}$ 13.146/2015), vários questionamentos surgiram quanto a obrigatoriedade de estabelecimentos privados de ensino promoverem a inclusão de alunos com deficiência, se adequando e assumindo integralmente tal ônus financeiro Em consonância com a decisão do Supremo Tribunal Federal que julgou improcedente a Ação Direta de Inconstitucionalidade n. 5357 e, conforme o demostrado no desenvolvimento do trabalho, o artigo 28 do referido Estatuto não contraria os dispositivos constitucionais alegados, no que tange ao dever dos estabelecimentos privados de prestar educação a alunos com deficiência.

Afirmar que o Estado tem o dever objetivo de tornar realidade a educação inclusiva não significa, de formar direta, que deve ele arcar com o ônus financeiro, até porque a pluralidade e a inclusão social que se pretendem na ordem constitucional não estariam resguardadas apenas com a assunção do ônus econômico. Educar vai além de prestar um serviço, consistindo em formar cidadãos de forma completa, visando o pleno desenvolvimento da pessoa, seu preparo para o exercício da cidadania e sua qualificação para o trabalho (artigo 205, da Constituição da República). Por essas razões, torna-se imperiosa a inclusão social no ambiente escolar regular de alunos com deficiências.

Interpretar a norma constitucional de forma a atribuir única e exclusivamente ao Estado o dever de educar pessoas que possuam alguma deficiência é destorcer o texto constitucional. Mesmo que não houvesse de forma expressa a indicação da sociedade e família como corresponsáveis, apenas dizer ser a educação dever do Estado, não necessariamente exclui a responsabilidade dos particulares, pelo contrário, tão somente afirma o dever do Estado de promovê-la e garanti-la, podendo até, para tanto, usar de seu poder de regulamente nas mais diversas formas, inclusive determinando à rede privada obediência ao Plano Nacional de Educação e normas afins para que possa explorar a atividade (artigo 209, I da $\mathrm{CF} / 88)$.

Ademais, afirmar no texto constitucional ser a educação efetivada pelo Estado mediante garantia de atendimento educacional especializado aos portadores de deficiência, não significa que será ela efetivamente prestada pelo Estado, mas apenas que o Estado garantirá sua efetividade. Como não fosse suficiente, o legislador ordinário determina que o referido ensino dar-se-á de forma preferencial na rede regular de ensino. Esta rede abrange tanto o ensino realizado por estabelecimentos públicos como particulares, devendo esses 
obedecer à Lei de Diretrizes e Bases da Educação Nacional (LDB), que já previa a educação inclusiva por toda a rede regular.

Tanto a Constituição da República, quanto a Lei de Diretrizes e Bases da Educação Nacional (LDB), bem como diversas outras normas anteriormente editadas, obedecendo à orientação constitucional, visam promover a educação inclusiva, garantido o acesso à educação como forma de dar efetividade ao direito da igualdade, e dessa forma possibilitar o mínimo de digna humana (princípio máximo do ordenamento jurídico brasileiro). Direito à igualdade, dignidade da pessoa humana e justiça social são valores supremos do Estado Democrático brasileiro, constituindo estes valores fundamento e objetivos fundamentais da República Federativa brasileira. Logo, deve o Estado promovê-los, agindo positivamente, para a manutenção do Estado Democrático de Direito, cujo modelo adotado garante a participação igualitária das minorias na consecução de seus fins.

Ponto controvertido, a ser discutido com mais profundidade, é o fato de que os preceitos contidos no parágrafo único, do artigo 28, do Estatuto da Pessoa com Deficiência (EPD), simplesmente transferem à iniciativa privada deveres que são próprios e inerentes ao poder público, sem criar mecanismos de compensação, contrapartida ou subsídio, com o desiderato de assegurar o equilíbrio econômico-financeiros dos contratos de prestação de serviços educacionais celebrados com as instituições privadas de ensino, em especial, considerando a vedação de repasse dos ônus aos pais ou familiares.

Para que não haja o desvirtuamento da participação colaborativa da sociedade na promoção do direito à educação, decorrente da transferência direta de obrigações do poder público aos particulares, indispensável que o Estado crie mecanismos e instrumentos de compensação, contrapartida ou subsídio destinados a assegurar o equilíbrio econômicofinanceiro dos contratos de prestação de serviços educacionais, estimulando as condutas sociais que reputa desejáveis, como forma de assegurar a efetividade das políticas de inclusão das pessoas com deficiência, sem prejuízo para a promoção da educação e garantia da livre iniciativa.

A discussão que envolve o direito fundamental social à educação é muito mais ampla, não comportando nesse pequeno ensaio apontar todas as problemáticas envolvidas, sob pena de não dar a elas o tratamento devido, capaz de ensejar a compreensão esperada. Assim, o objetivo do presente trabalho não foi esgotar a temática proposta, apenas contribuir para o debate e para a construção de soluções que seja capazes de conciliar e assegurar a máxima efetividade dos direitos fundamentais. 
Referências

ATIQUE, Andraci Lucas Veltroni; VELTRONI, Alexandre Lucas. A Pessoa Portadora de Deficiência e a Educação no Brasil. Doutrinas Essenciais de Direitos Humanos, São Paulo, v. 4, p.907-942, ago. 2011.

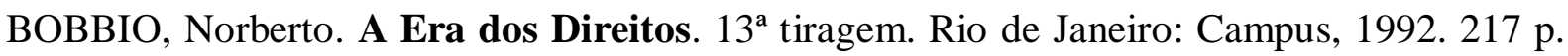
Tradução de: Carlos Nelson Coutinho.

BONAVIDES, Paulo. Curso de Direito Constitucional. 15. ed. São Paulo: Malheiros, 2004, p. 806.

BRASIL. SUPREMO TRIBUNAL FEDERAL. Notícias STF: Escolas particulares devem cumprir obrigações do Estatuto da Pessoa com Deficiência, decide STF. 2016. Disponível em: $<$ http://www.stf.jus.br/portal/cms/verNoticiaDetalhe.asp?idConteudo=318570>. Acesso em: 02 mai. 2017.

BERGARA, Paola Neves dos Santos e GONÇALVES Bruno Tadeu Radtke. A Revolução Francesa e seus Reflexos nos Direitos Humanos. In: ETIC - ENCONTRO DE INICIAÇÃO CIENTÍFICA, 4., 2008, Presidente Prudente. Revistas Eletrônicas da Toledo Presidente Prudente. Presidente Prudente: ETIC, 2008. 12 p. Disponível em:<http://intertemas.unitoledo.br/revista/index.php/ETIC/article/viewFile/1718/1638>.

BONAVIDES, Paulo. Curso de direito constitucional. 23ª ed. São Paulo: Malheiros, 2008.

GALDINO, Flávio. Introdução à teoria dos custos dos direitos: direitos não nascem em árvores. Rio de Janeiro: Lúmen Júris, 2005, 380 p.

GOMES, Dinaura Godinho Pimentel. O processo de afirmação dos direitos fundamentais: evolução histórica, interação expansionista e perspectivas de efetivação. Revista de Direito Constitucional e Internacional, São Paulo, v.11, n.45, p.109-140, out./dez. 2003.

GOMES, Sergio Alves. O Princípio Constitucional da Dignidade da Pessoa Humana e o Direito Fundamental à Educação. Doutrinas Essenciais de Direitos Humanos, São Paulo, v. 3, p.1101-1157, ago. 2011.

GUERRA FILHO, Willis Santiago. A filosofia do direito: aplicada ao direito processual e à teoria da Constituição. São Paulo: Atlas, 2001.

MELO, Mônica de. O Princípio da Igualdade à Luz das Ações Afirmativas: O Enfoque da Discriminação Positiva. Doutrinas Essenciais de Direito Constitucional e Internacional, São Paulo, v. 4, p. 1375-1407, ago. 2011.

MELLO, Claudio Ari. Os direitos sociais e a teoria discursiva do direito. Revista de Direito Administrativo, Rio de Janeiro, n. 224, p. 239-284, abr./maio./jun de 2001.

PESSOA, Eudes André. A Constituição Federal e os Direitos Sociais Básicos ao Cidadão Brasileiro. In: Âmbito Jurídico, Rio Grande, XIV, n. 89, jun. 2011. Disponível em: 
<http://www.ambitojuridico.com.br/site/index.php?n_link=revista_artigos_leitura\&artigo_id= 9623>. Acesso em: 29 abr. 2017.

COMPARATO, Fábio Konder. Afirmação histórica dos direitos humanos. $2^{\mathrm{a}}$. ed., rev. e ampl. São Paulo: Saraiva, 2001. 488 p.

ROCHA, Marcelo Hugo da. O Direito Fundamental à Educação Inclusiva e o Estatuto da Pessoa com Deficiência. Revistas dos Tribunais, São Paulo, v. 963, p.129-151, jan. 2016.

STERN, Klaus. Derecho Del Estado de la Republica Federal Alemana. Javier Pérez Royo e Pedro Cruz Villalón (Trad.). Madrid: Centro de Estudios Constitucionales, 1987.

SILVA, José Afonso da. Curso de Direito Constitucional Positivo. 26a ed. rev. e atual. São Paulo: Ed. Malheiros, 2005. 924 p.

SANTOS, Erik. A Educação Especial em Face a Convenção da Unesco contra a Discriminação no Campo da Educação. Revista de Direito Educacional, São Paulo, v. 5, p.125-139, jan. 2012. 